\title{
Molecular Engineering in Catalysis: Immobilization of Shvo's Ruthenium Catalyst to Silica Coated Magnetic Nanoparticles
}

\author{
Dongmei He', István T. Horváth²,2* \\ 1 Department of Chemistry, City University of Hong Kong, Kowloon, 83 Tat Chee Avenue, Hong Kong, Hong Kong S. A. R. \\ 2 Department of Chemical and Environmental Process Engineering, Faculty of Chemical Technology and Biotechnology, \\ Budapest University of Technology and Economics, H-1111 Budapest, 8 Budafoki Street, Hungary \\ * Corresponding author, e-mail: isvan.t.horvath@edu.bme.hu
}

Received: 29 March 2020, Accepted: 02 July 2020, Published online: 21 October 2020

\begin{abstract}

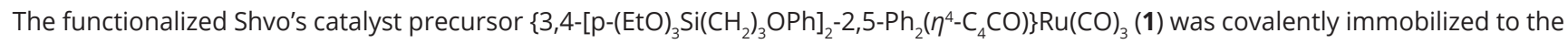
surface of magnetic nanoparticles, MNPs, including magnetite $\left(\mathrm{Fe}_{3} \mathrm{O}_{4}\right)$ and magnetite covered by one, two and three independently added silica $\left(\mathrm{SiO}_{2}\right)$ coatings $\left(\mathrm{Fe}_{3} \mathrm{O}_{4} @ \mathrm{SiO}_{2}, \mathrm{Fe}_{3} \mathrm{O}_{4} @ \mathrm{SiO}_{2} @ \mathrm{SiO}_{2}, \mathrm{Fe}_{3} \mathrm{O}_{4} @ \mathrm{SiO}_{2} @ \mathrm{SiO}_{2} @ \mathrm{SiO}_{2}\right)$ resulting in the corresponding ruthenium catalysts $\mathrm{Fe}_{3} \mathrm{O}_{4} @ \mathrm{Ru}(\mathbf{2 a}), \mathrm{Fe}_{3} \mathrm{O}_{4} @ \mathrm{SiO}_{2} @ \mathrm{Ru}(\mathbf{2} \mathbf{b}), \mathrm{Fe}_{3} \mathrm{O}_{4} @ \mathrm{SiO}_{2} @ \mathrm{SiO}_{2} @ \mathrm{Ru}\left(\mathbf{2 c}\right.$ ), and $\mathrm{Fe}_{3} \mathrm{O}_{4} @ \mathrm{SiO}_{2} @ \mathrm{SiO}_{2} @ \mathrm{SiO}_{2} @ \mathrm{Ru}$ (2d). These catalysts were characterized by FT-IR, TEM, EDX, powder XRD, BET surface area analysis and BJH pore size and volume analysis. The catalytic performances of $\mathbf{2 a - 2} \mathbf{d}$ were tested for the conversion of levulinic acid (LA) to gamma-valerolactone (GVL) using formic acid (FA) as the hydrogen source. The catalysts were separated from the reaction mixture by using an external magnet. Catalysts on the silica coated MNPs showed higher activity than that of immobilized directly to $\mathrm{Fe}_{3} \mathrm{O}_{4}$. There were no significant differences in TONs, TOFs and yields of GVL using catalysts $\mathbf{2 b}-\mathbf{2} \mathbf{d}$. Leaching test of the four catalysts showed that by increasing the number of independent silica coatings on the surface of magnetite significantly decreased iron leaching. The recyclability of $\mathbf{2} \mathbf{b}$ was investigated and it was reused several times without significant loss of the catalytic activity. Hot filtration test of $\mathbf{2} \mathbf{c}$ and $\mathbf{2} \mathbf{d}$ has established that the catalytic activity was due to the supported ruthenium catalyst and not from some active ruthenium species leached from the solid support to the solution under the reaction conditions.
\end{abstract}

\section{Keywords}

immobilization, Shvo's catalyst, ruthenium, silica coated magnetite, levulinic acid, formic acid, gamma-valerolactone

\section{Introduction}

Sustainable chemistry and chemical processes should use resources, including energy, at a rate at which they can be replaced naturally, and the generation of waste cannot be faster than the rate of their remediation [1]. Since fossil resources will run out imminently, the transition to biomass based chemical enterprise is inevitable. The valorization of agricultural residues and food wastes has been one of the possible strategies [2] to integrate biomass based processes with established technologies in today's refineries to produce carbon-based platform chemicals [3]. Conversion of polysaccharides could lead to the formation of furfural (FF) or 5-hydroxy-methyl-furfural (HMF) (Scheme 1) [4]. Chitin could be the source of acetic acid (AA), ammonia $\left(\mathrm{NH}_{3}\right)$, and HMF [5]. The hydration of HMF results in the formation of equimolar levulinic acid (LA) and formic acid (FA) [6]. The reduction of FF to furfuryl

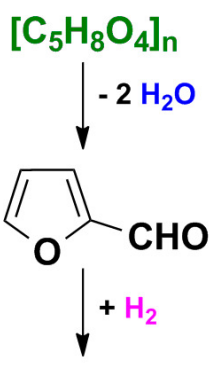

$$
\left[\mathrm{C}_{6} \mathrm{H}_{10} \mathrm{O}_{5}\right]_{\mathrm{n}} \quad\left[\mathrm{C}_{8} \mathrm{H}_{13} \mathrm{O}_{5} \mathrm{~N}\right]_{n}
$$<smiles>OCc1ccco1</smiles>

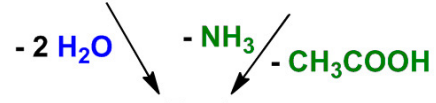<smiles>Oc1ccccc1</smiles><smiles>CCc1ccc(C=O)o1</smiles>

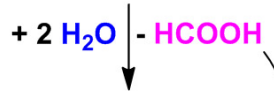<smiles>CC(=O)CCC(=O)OCC(C)(C)C(=O)OCCC(=O)O</smiles>

Scheme 1 Conversion of hemicellulose, cellulose and chitin to carbonbased platform chemicals. 
alcohol (FFA) [7] followed by the acid catalyzed hydroisomerization of FFA leads to the formation of LA [8]. The transfer-hydrogenation of LA with FA leads to the formation of 4-hydroxy valericacid (4-HVA), which can readily undergo dehydration to form gamma-valerolactone (GVL) [9]. The latter can be used as a sustainable liquid for producing energy and carbon-based chemicals [10].

The successful application of catalysts depend on the molecular level control of catalytic performance and the facile separation of the products and recycling the catalyst. Immobilization of homogeneous catalysts has been a well-studied approach to combine high yields of homogeneous catalysts with efficient separations of heterogeneous catalytic systems [11]. The attachment of the ligands of transition metal homogeneous catalysts to the surface of inorganic or organic solid supports via covalent bonds has been frequently used to prepare immobilized catalysts. However, the separation of the immobilized catalyst by simple filtration could run into problems if insoluble solid products and/or side products form in the reaction. An attractive approach for solid-solid separation is the use of magnetic solid supports [12] including magnetic iron cores with non-porous or highly porous silica layers $[13,14]$ which can be removed from non-magnetic solids by a magnet.

The well-known Shvo's catalyst system [15] (Scheme 2) are among the most selective homogeneous transfer-hydrogenation catalysts for the conversion of LA and FA to GVL via 4-HVA [9]. The ruthenium catalyst precursors contain two phenyl substituents at the 2,5-positions and two para-alkoxy-phenyl substituents at the 3,4-positions of the $\eta^{4}$-cyclopentadienone and the $\eta^{5}$-cyclopentadienyl ligands attached to the ruthenium. ${ }^{15}$

Although the Shvo's catalysts were immobilized to silica some time ago $[16,17]$ they were not used for transfer-hydrogenation of LA with FA. We have recently reported the synthesis of silica supported Shvo's catalysts, which were successfully tested for the conversion of LA and FA to GVL in good to high yields [18]. Since the

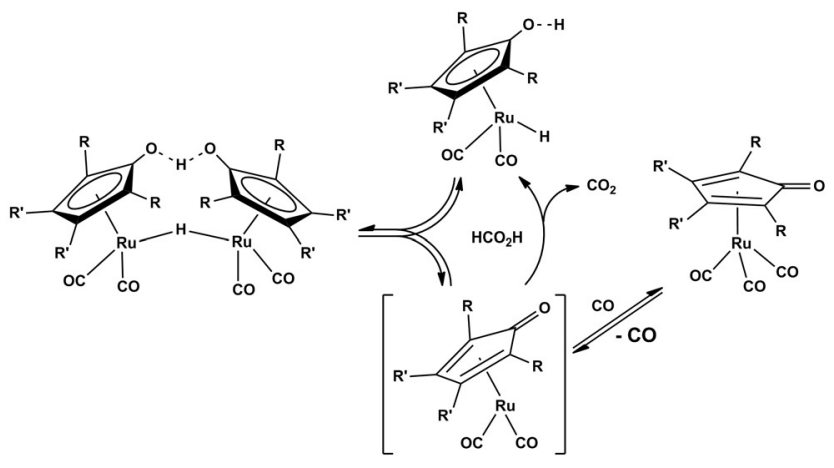

Scheme 2 Shvo's ruthenium catalyst system. production of LA and FA from carbohydrates via HMF is typically accompanied by the formation of insoluble solid side-products such as humins, the recycling of the silica supported Shvo's catalysts could be rather cumbersome. We report here the immobilization of Shvo's catalyst to silica coated magnetic nanoparticles (MNPs), which offers easy catalyst separation from both liquids and solids.

\section{Experimental}

Unless stated otherwise, reactions were carried out under nitrogen by using standard Schlenk techniques. All solvents were purified and dried by using standard methods. Ruthenium (III) chloride hydrate, cesium carbonate, sodium iodide, sodium hydroxide, ammonium hydroxide, nitric acid, $\mathrm{FeCl}_{3} \times 6 \mathrm{H}_{2} \mathrm{O}, \mathrm{FeCl}_{2} \times 4 \mathrm{H}_{2} \mathrm{O}$, tetraethyl orthosilicate (TEOS), levulinic acid (LA), formic acid (FA), dimethyl sulfone, $\mathrm{CD}_{2} \mathrm{Cl}_{2}, \mathrm{CDCl}_{3}, \mathrm{~d}_{8}$-toluene, and $\mathrm{d}_{6}$-DMSO were purchased from commercial sources (Sigma-Aldrich, Acros and Merck) and used as received. Literature methods were used for the synthesis of $\left\{3,4-\left[p-(\mathrm{EtO})_{3} \mathrm{Si}\left(\mathrm{CH}_{2}\right)_{3} \mathrm{OPh}\right]_{2}-\right.$ $\left.2,5-\mathrm{Ph}_{2}\left(\eta^{4}-\mathrm{C}_{4} \mathrm{CO}\right)\right\} \mathrm{Ru}(\mathrm{CO})_{3}$ (1) [18], $\left\{3,4-[p-\mathrm{MeOPh}]_{2}-2,5-\right.$ $\left.\mathrm{Ph}_{2}\left(\eta^{4}-\mathrm{C}_{4} \mathrm{CO}\right)\right\} \mathrm{Ru}(\mathrm{CO})_{3}$ (3) [9] $\mathrm{Ru}_{3}(\mathrm{CO})_{12}$ [19], (3-iodo-propyl)-triethoxysilane (IPTES) [20], $\mathrm{Fe}_{3} \mathrm{O}_{4}$ [21], and $\mathrm{Fe}_{3} \mathrm{O}_{4} @$ $\mathrm{SiO}_{2}$ [22]. All reactions were monitored by Thin-Layer Chromatography (TLC) on Merck aluminium sheets (silica gel 60 F254) and visualized with UV light. E. Merck silica gel 60 (230-400 mesh) was used for column chromatography.

${ }^{1} \mathrm{H}$ - and ${ }^{13} \mathrm{C}-\mathrm{NMR}$ were measured with Bruker (400 or $600 \mathrm{MHz}$ ) at room temperature. All chemical shifts were recorded in ppm relative to residual $\mathrm{CH}_{2} \mathrm{Cl}_{2}$, $\mathrm{CHCl}_{3}$, toluene, or DMSO on the $\delta$ scale. MS and HRMS were measured on a Thermo-Finnigan MAT $95 \mathrm{KL}$ or Bruker 9.4 Tesla Fourier Transform Ion Cyclotron Resonance Mass spectrometer. IR spectra of samples in $\mathrm{KBr}$ pellets or thin films were recorded in the range of $400-4000 \mathrm{~cm}^{-1}$ using an AVATAR 360 FT-IR spectrometer. Transmission Electron Microscopy (TEM) was performed by using FEI/Philips Tecnai 12 BioTWIN microscope. Scanning Electron Microscopy (SEM) and Energy Dispersive X-Ray Spectroscopy (EDX) were performed by using a FEI/Philips XL30 Esem-FEG microscope. Brunauer-Emmett-Teller (BET) surface area analysis and Barrett-Joyner-Halenda (BJH) pore size and volume analysis were conducted by Micromeritics Tri Star 3000 Surface Area and Porosity Analyzer. Powder X-ray diffraction (XRD) patterns were obtained with a Siemens D500/Philips X-Pert. Metal analysis was done by a Perkin Elmer Elan 6100 DRC Inductively Coupled Plasma-Mass Spectrometer (ICP-MS). 


\subsection{Preparation of magnetite and silica-coated} magnetite supports

\subsubsection{Magnetite $\left(\mathrm{Fe}_{3} \mathrm{O}_{4}\right)$}

To a stirred solution of $\mathrm{FeCl}_{3} \times 6 \mathrm{H}_{2} \mathrm{O}(5.07 \mathrm{~g}, 18.76 \mathrm{mmol})$ and $\mathrm{FeCl}_{2} \times 4 \mathrm{H}_{2} \mathrm{O}(1.86 \mathrm{~g}, 9.38 \mathrm{mmol})$ in deionized water $(150 \mathrm{~mL})$ in a $250 \mathrm{~mL}$ three-neck round-bottom flask equipped with a condenser and a mechanical stirrer, $\mathrm{NaOH}$ was added (3.00 g, $75.00 \mathrm{mmol})$ at room temperature under nitrogen. The reaction mixture was stirred with a mechanical stirrer at room temperature for 30 minutes and then heated at $80^{\circ} \mathrm{C}$ for 1 hour. The formation of black precipitate was observed, which was separated using an external magnet and washed with ethanol five times and then with deionized water five times. It was dried overnight under vacuum at room temperature. FTIR (in KBr) in $\mathrm{cm}^{-1}: 591\left(\mathrm{~s}, \mathrm{v}_{\mathrm{Fe}-\mathrm{O}}\right), 3431\left(\mathrm{br}, \mathrm{n}_{\mathrm{O}-\mathrm{H}}\right)$. The EDX spectrum displayed $72.29 \mathrm{w} \%$ iron in the magnetite, the calculated value was $72.36 \mathrm{w} \%$. The TEM image showed that the average diameter of the $\mathrm{Fe}_{3} \mathrm{O}_{4}$ core was less than $10 \mathrm{~nm}$.

\subsubsection{Magnetite covered by one layer of silica $\left(\mathrm{Fe}_{3} \mathrm{O}_{4} @\right.$} $\mathrm{SiO}_{2}$ )

$\mathrm{Fe}_{3} \mathrm{O}_{4}$ nanoparticles $(100 \mathrm{mg}$ ) were placed in $20 \mathrm{~mL}$ of deionized water in a $250 \mathrm{~mL}$ three-neck round-bottom flask equipped with a condenser and a mechanical stirrer. It was dispersed by ultra-sonication at room temperature for 30 minutes under nitrogen. To the resulting suspension, we successively added $100 \mathrm{~mL}$ of ethanol and $2 \mathrm{~mL}$ of TEOS. Then, $4 \mathrm{~mL}$ of ammonium hydroxide solution $\left(25 \% \mathrm{NH}_{3}\right)$ was added. The reaction mixture was stirred at room temperature for 24 hours. A dark brown precipitate was collected by using an external magnet. The precipitate was washed with ethanol five times and deionized water five times. Subsequently, it was dried overnight under vacuum at room temperature. FTIR (in KBr) in $\mathrm{cm}^{-1}: 1095$ (str, $\mathrm{n}_{\text {Si-O-Si }}$ ), $805\left(\mathrm{w}, \mathrm{n}_{\mathrm{Si}-\mathrm{O}-\mathrm{Si}}\right), 3431\left(\mathrm{br}, \mathrm{n}_{\mathrm{O}-\mathrm{H}}\right)$.

\subsubsection{Magnetite covered by two layers of silica $\left(\mathrm{Fe}_{3} \mathrm{O}_{4} @\right.$} $\mathrm{SiO}_{2} @ \mathrm{SiO}_{2}$ )

$\mathrm{Fe}_{3} \mathrm{O}_{4} @ \mathrm{SiO}_{2}$ nanoparticles (100 mg) were placed in $20 \mathrm{~mL}$ of deionized water in a $250 \mathrm{~mL}$ three-neck round-bottom flask equipped with a condenser and a mechanical stirrer. It was dispersed by ultrasonication at room temperature for $30 \mathrm{~min}$ under nitrogen. To the resulting suspension, we successively added $100 \mathrm{~mL}$ of ethanol and $2 \mathrm{~mL}$ of TEOS. Subsequently, $4 \mathrm{~mL}$ of ammonium hydroxide solution $\left(25 \% \mathrm{NH}_{3}, 13.38 \mathrm{~mol} / \mathrm{L}\right)$ was added. After stirring at room temperature for 24 hours, a brown precipitate was collected by using an external magnet. The precipitate was washed with ethanol five times and deionized water five times. Then, it was dried overnight under vacuum at room temperature. FTIR (in $\mathrm{KBr}$ ) in $\mathrm{cm}^{-1}: 1095$ (str, $\mathrm{n}_{\text {Si-O-Si }}$ ), $809\left(\mathrm{w}, \mathrm{n}_{\mathrm{Si}-\mathrm{O}-\mathrm{Si}}\right), 3412\left(\mathrm{br}, \mathrm{n}_{\mathrm{O}-\mathrm{H}}\right)$.

\subsubsection{Magnetite covered by three layers of silica} $\left(\mathrm{Fe}_{3} \mathrm{O}_{4} @ \mathrm{SiO}_{2} @ \mathrm{SiO}_{2} @ \mathrm{SiO}_{2}\right)$ $\mathrm{Fe}_{3} \mathrm{O}_{4} @ \mathrm{SiO}_{2} @ \mathrm{SiO}_{2}$ nanoparticles (100 mg) were placed in $20 \mathrm{~mL}$ of deionized water in a $250 \mathrm{~mL}$ three-neck roundbottom flask equipped with a condenser and a mechanical stirrer. It was dispersed by ultra-sonication at room temperature for 30 minutes under nitrogen. To the resulting suspension, $100 \mathrm{~mL}$ of ethanol and $2 \mathrm{~mL}$ of TEOS were successively added. Then, $4 \mathrm{~mL}$ of ammonium hydroxide solution $\left(25 \% \mathrm{NH}_{3}\right)$ was added. After stirring at room temperature for 24 hours, a light brown precipitate was collected by using an external magnet. The precipitate was washed with ethanol five times and deionized water five times. It was then dried overnight under vacuum at room temperature. FTIR (in KBr) in $\mathrm{cm}^{-1}: 1095$ (str, $\mathrm{n}_{\mathrm{Si}-\mathrm{O}-\mathrm{Si}}$ ), $806\left(\mathrm{w}, \mathrm{n}_{\mathrm{Si}-\mathrm{O}-\mathrm{Si}}\right), 3418\left(\mathrm{br}, \mathrm{n}_{\mathrm{O}-\mathrm{H}}\right)$.

\subsection{Preparation of MNPs-supported Shvo's catalysts}

$6.0 \mathrm{~mL}$ of $\mathrm{d}_{8}$-toluene was added to a $25 \mathrm{~mL}$ threeneck round-bottom flask equipped with a condenser and a mechanical stirrer. A sample of $0.1 \mathrm{mmol}$ of $\left\{3,4-\left[p-(\mathrm{EtO})_{3} \mathrm{Si}\left(\mathrm{CH}_{2}\right)_{3} \mathrm{OPh}\right]_{2}-2,5-\mathrm{Ph}_{2}\left(\eta^{4}-\mathrm{C}_{4} \mathrm{CO}\right)\right\} \mathrm{Ru}(\mathrm{CO})_{3}$ (1) and dimethyl sulfone (internal standard, $0.044 \mathrm{mmol}$, $4.1 \mathrm{mg}$ ) were added. At this point, quantitative ${ }^{1} \mathrm{H}-\mathrm{NMR}$ $(t=0 \mathrm{~h})$ was carried out. Then, $1.0 \mathrm{~g}$ of MNPs $\left(\mathrm{Fe}_{3} \mathrm{O}_{4}\right.$, $\mathrm{Fe}_{3} \mathrm{O}_{4} @ \mathrm{SiO}_{2}, \mathrm{Fe}_{3} \mathrm{O}_{4} @ \mathrm{SiO}_{2} @ \mathrm{SiO}_{2}$, or $\mathrm{Fe}_{3} \mathrm{O}_{4} @ \mathrm{SiO}_{2} @ \mathrm{SiO}_{2} @$ $\mathrm{SiO}_{2}$ ) was added, and the resulting suspension was sonicated for 10 minutes at room temperature. The reaction mixture was stirred at room temperature for 48 hours. The flask was then placed in proximity to an external magnet, and the solution was separated from the MNPs with a Pasteur pipette and analyzed by quantitative ${ }^{1} \mathrm{H}-\mathrm{NMR}$ to determine the catalyst loading. The remaining particles were washed 3 times with toluene and dried overnight under vacuum at room temperature to afford Ru-MNP catalysts $\mathrm{Fe}_{3} \mathrm{O}_{4} @ \mathrm{Ru}(\mathbf{2 a}), \mathrm{Fe}_{3} \mathrm{O}_{4} @$ $\mathrm{SiO}_{2} @ \mathrm{Ru}(\mathbf{2 b}), \mathrm{Fe}_{3} \mathrm{O}_{4} @ \mathrm{SiO}_{2} @ \mathrm{SiO}_{2} @ \mathrm{Ru}(\mathbf{2})$, and $\mathrm{Fe}_{3} \mathrm{O}_{4} @$ $\mathrm{SiO}_{2} @ \mathrm{SiO}_{2} @ \mathrm{SiO}_{2} @ \mathrm{Ru}(\mathbf{2 d})$. The catalyst loading was confirmed by ICP-MS analysis. 


\subsection{Conversion of levulinic acid and formic acid to} gamma-valerolactone in the presence of homogeneous or immobilized Shvo's catalysts

\subsubsection{Conversion of LA and FA to GVL with Homogeneous Shvo's catalysts}

To a mixture of LA (1.28 g, $11.02 \mathrm{mmol})$ and FA (1.14 g, $24.77 \mathrm{mmol}$ ) in $4 \mathrm{~mL}$ of 1,4-dioxane in a $25 \mathrm{~mL}$ two-neck round-bottom flask equipped with a condenser, approximately $0.03 \mathrm{mmol}$ of homogeneous Shvo's catalysts 1 or 3 was added and stirred at $90{ }^{\circ} \mathrm{C}$. The yields of GVL at different times were determined by quantitative ${ }^{1} \mathrm{H}-\mathrm{NMR}$.

\subsubsection{Conversion of LA and FA to GVL with immobilized Shvo's catalysts without solvent}

To a mixture of LA (2 g, $17.2 \mathrm{mmol})$ and FA (2 g, $43.4 \mathrm{mmol}$ ) in a $25 \mathrm{~mL}$ three-neck round-bottom flask equipped with a condenser and a mechanical stirrer, a certain amount of MNP-supported Shvo's catalyst 2a-2d was added. The resulting suspension was stirred at $90{ }^{\circ} \mathrm{C}$ for a given time. At the end of the reaction, the flask was placed in the proximity of an external magnet and the solution was separated from the catalyst with a Pasteur pipette. The yields of GVL at different times were determined by quantitative ${ }^{1} \mathrm{H}-\mathrm{NMR}$.

In the case of recycling experiments, LA (2 g, $17.2 \mathrm{mmol}$ ) and FA (2 g, $43.4 \mathrm{mmol})$ were added, and the external magnet was removed from the proximity of the flask to start a new experiment.

\subsubsection{Conversion of LA and FA to GVL with immobilized Shvo's catalysts in 1,4-dioxane}

To a solution of LA (1.28 g, $11.02 \mathrm{mmol})$ and FA (1.14 g, $24.77 \mathrm{mmol}$ ) in $4 \mathrm{~mL}$ of 1,4-dioxane in a $25 \mathrm{~mL}$ threeneck round-bottom flask equipped with a condenser and a mechanical stirrer, a certain amount of MNP-supported Shvo-type catalyst $\mathbf{2 a - 2 d}$ was added. The resulting suspension was stirred at $90^{\circ} \mathrm{C}$ for a given time. At the end of the reaction, the flask was placed in proximity to an external magnet, and the solution was separated from the catalyst with a Pasteur pipette. The yields of GVL at different times were determined by quantitative ${ }^{1} \mathrm{H}-\mathrm{NMR}$.

In the case of recycling experiments, LA (1.28 g, $11.02 \mathrm{mmol})$, FA (1.14 g, $24.77 \mathrm{mmol})$, and $4 \mathrm{~mL}$ of 1,4-dioxane were added, and the external magnet was removed from the proximity of the flask to start a new experiment.

\subsection{ICP-MS analysis of Ru and Fe concentration}

2.4.1 Determination of the $\mathrm{Ru}$ and Fe concentration in immobilized catalysts

In $3 \mathrm{~mL}$ concentrated nitric acid, $35 \mathrm{mg}$ of immobilized Shvo's catalysts $\mathbf{2 a}-\mathbf{2 d}$ was digested at $80^{\circ} \mathrm{C}$ for 24 hours. Each solution was then diluted to $25 \mathrm{~mL}$ using deionized water. Corresponding blank samples were prepared in the same way, then ICP-MS analysis of each sample was conducted.

\subsubsection{Determination of $\mathrm{Ru}$ and Fe leaching in organic residue after reaction}

After each transfer hydrogenation of LA with FA in the presence of heterogenized Shvo's catalysts $\mathbf{2 a - 2 d}$, the reaction solution was separated from the catalyst by filtration or by using an external magnet; the solution was concentrated under reduced pressure. Then, the organic residue was digested in $3 \mathrm{~mL}$ of concentrated nitric acid at $80{ }^{\circ} \mathrm{C}$ for 24 hours. Each solution was then diluted to $25 \mathrm{~mL}$ using deionized water. Corresponding blank samples were prepared in the same way, then ICP-MS analysis was conducted.

\subsection{Hot filtration test of immobilized Shvo's catalysts}

To a solution of $1 \mathrm{~mL}$ LA $(1.28 \mathrm{~g}, 11.02 \mathrm{mmol})$ and $1 \mathrm{~mL}$ FA (1.14 g, $24.77 \mathrm{mmol})$ in $2 \mathrm{~mL}$ of $\mathrm{d}_{6}$-DMSO in a $25 \mathrm{~mL}$ three-neck round-bottom flask equipped with a condenser and a mechanical stirrer, a certain amount of MNPs-supported Shvo-type catalyst $(0.37$ g 2 c or 0.33 g 2d was added. The resulting suspension was stirred at $90{ }^{\circ} \mathrm{C}$ for 24 hours. The flask was then placed in proximity to an external magnet, and $2 \mathrm{~mL}$ of the reaction solution was separated from the catalyst with a Pasteur pipette and put in a syringe equipped with a $45 \mu \mathrm{m}$ PTFE syringe filter. The filtered portion was then added to a septum capped NMR tube for $1 \mathrm{H}-\mathrm{NMR}$ test. At this point, a conversion of GVL was recorded at $t=24 \mathrm{~h}$. The remaining solution with the catalyst and the filtered portion in the NMR tube were heated to $90{ }^{\circ} \mathrm{C}$ for another 24 hours. Then, ${ }^{1} \mathrm{H}-\mathrm{NMR}$ spectra of both portions were recorded to obtain the conversions of GVL at $t=48 \mathrm{~h}$.

\section{Results and discussions}

Although the equimolar mixture of LA and FA can be produced from carbohydrates via HMF (Scheme 1), the formation of significant amounts of solid side products, including humins, represents a serious challenge for the separation 


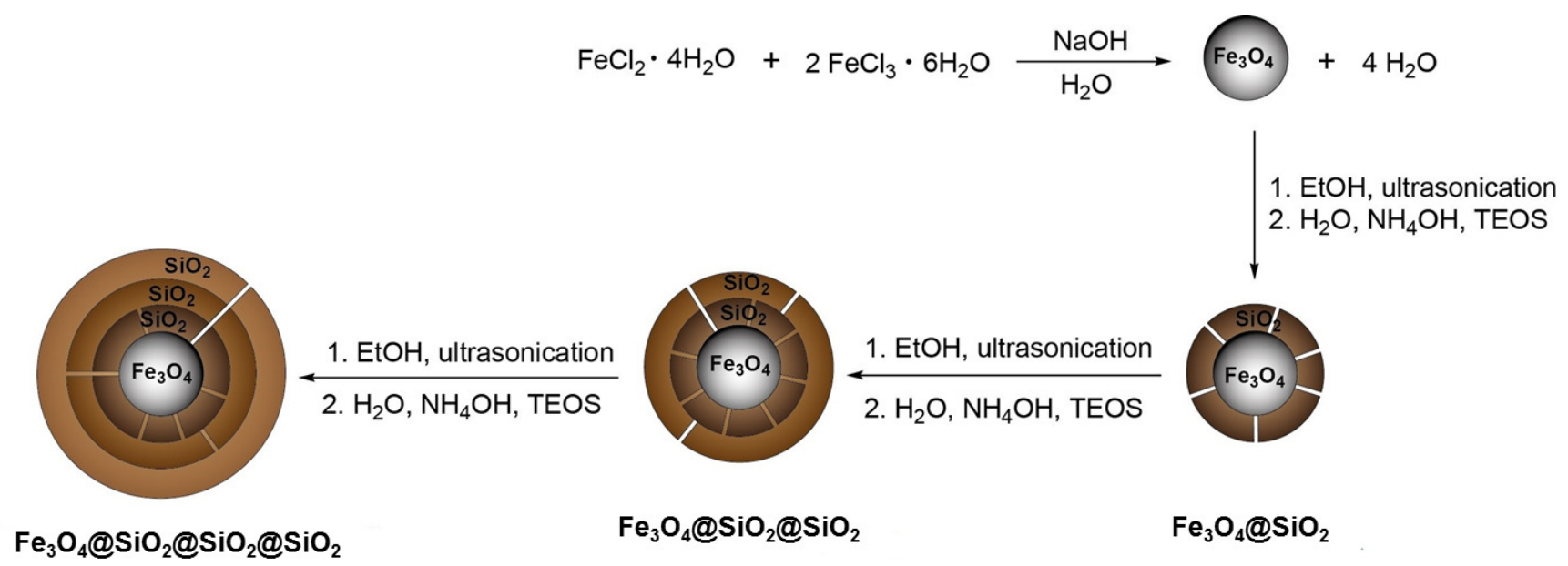

Scheme 3 Preparation of magnetic supports.

of silica supported Shvo's catalysts from GVL [18]. One of the possible startegies to overcome a solid-solid separation issue is the use of magnetic silica supported Shvo's catalyst, which could be "pulled away" from the reaction mixture by a simple external magnet [12, 23, 24].

Four magnetic supports including magnetite $\left(\mathrm{Fe}_{3} \mathrm{O}_{4}\right)$ and magnetite covered by one, two and three independently added silica coatings, $\mathrm{Fe}_{3} \mathrm{O}_{4} @ \mathrm{SiO}_{2}, \mathrm{Fe}_{3} \mathrm{O}_{4} @ \mathrm{SiO}_{2} @ \mathrm{SiO}_{2}$, and $\mathrm{Fe}_{3} \mathrm{O}_{4} @ \mathrm{SiO}_{2} @ \mathrm{SiO}_{2} @ \mathrm{SiO}_{2}$ were prepared (Scheme 3).

The magnetite $\left(\mathrm{Fe}_{3} \mathrm{O}_{4}\right)$ nanoparticles were prepared by the co-precipitation method under $\mathrm{N}_{2}$ as described previously [21]. Ultra-sonication was used to obtain smaller nanoparticles, which could be readily separated from the reaction system by placing an external magnet next to the vial (Fig. 1).

The $\mathrm{Fe}_{3} \mathrm{O}_{4}$ nanocrystals were black and could be released to the reaction mixture by removing the external magnet and shaking the vial. No rust was observed, which indicated that no oxidation of $\mathrm{Fe}_{3} \mathrm{O}_{4}$ to $\mathrm{Fe}_{2} \mathrm{O}_{3}$ occurred, as expected. The $\mathrm{Fe}_{3} \mathrm{O}_{4}$ nanoparticles have a spherical structure, which can be seen from the TEM image at high magnification (Fig. 2 (a)). The average diameter of the $\mathrm{Fe}_{3} \mathrm{O}_{4}$ core was less than $10 \mathrm{~nm}$ and the nanoparticles were uniform.

The EDX spectrum of $\mathrm{Fe}_{3} \mathrm{O}_{4}$ (Fig. 3) showed that the weight percentage of iron was $72.29 \%$ (calc.: $72.36 \%$ ) and the atom percentage of oxygen was $42.77 \%$, (calc.: $42.85 \%$ ).

A solution of the functionalized Shvo's catalyst precursor $\quad\left\{3,4-\left[p-(\mathrm{EtO})_{3} \mathrm{Si}\left(\mathrm{CH}_{2}\right)_{3} \mathrm{OPh}\right]_{2}-2,5-\mathrm{Ph}_{2}\left(\eta^{4}-\mathrm{C}_{4} \mathrm{CO}\right)\right\}$ $\mathrm{Ru}(\mathrm{CO})_{3}(\mathbf{1})$ was attached to $\mathrm{Fe}_{3} \mathrm{O}_{4}$ nanoparticles in $\mathrm{d}_{8}$-toluene at room temperature. The resulting $\mathrm{Fe}_{3} \mathrm{O}_{4} @ \mathrm{Ru}(\mathbf{2 a})$ catalyst was separated from the solution by using an external magnet. The successful immobilization was indicated

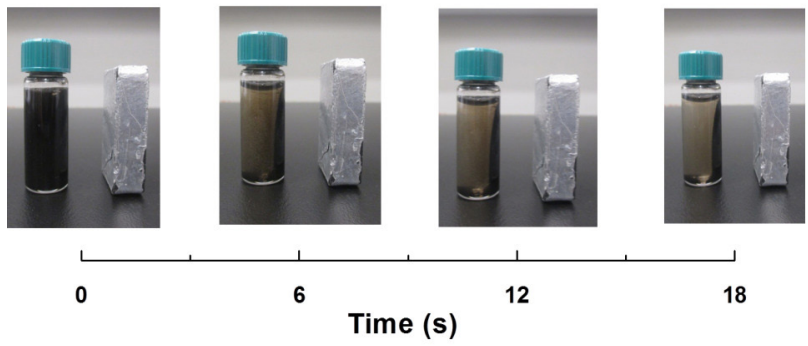

Fig. 1 Recovery of $\mathrm{F}_{3} \mathrm{O}_{4}$ magnetic nanocrystals from the reaction mixture using an external magnet.

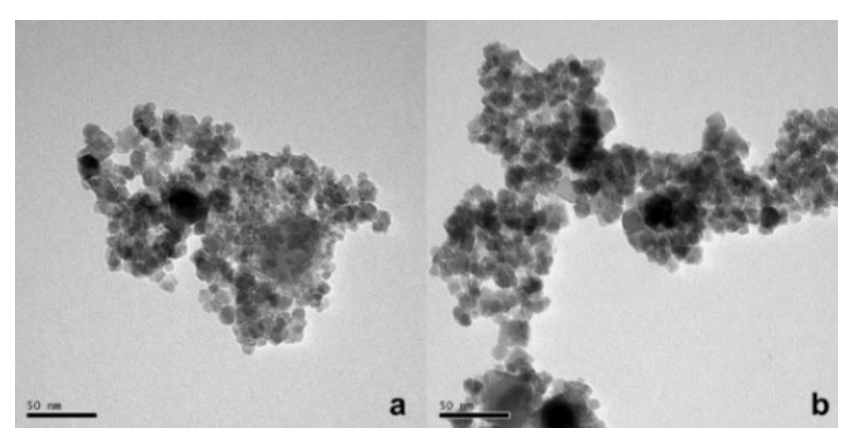

Fig. 2 TEM images of $\mathrm{Fe}_{3} \mathrm{O}_{4}$ (a) and (2a) (b).

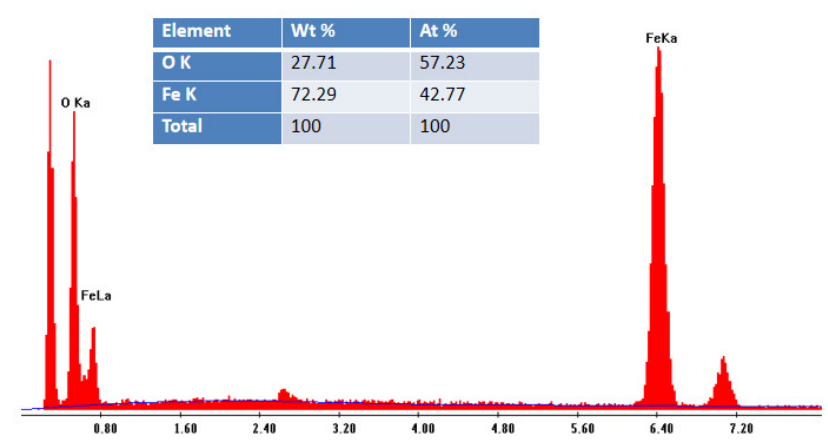

Fig. 3 The EDX spectrum of $\mathrm{Fe}_{3} \mathrm{O}_{4}$. 

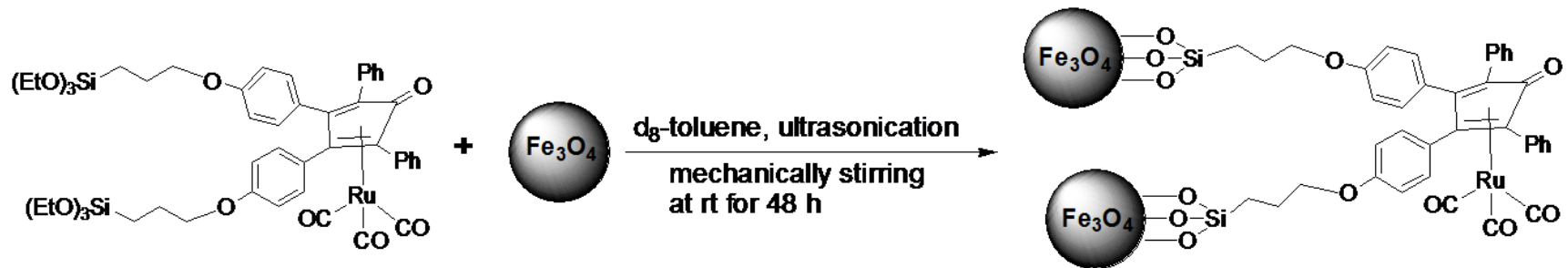

Scheme 4 Preparation of magnetic catalyst (2a).

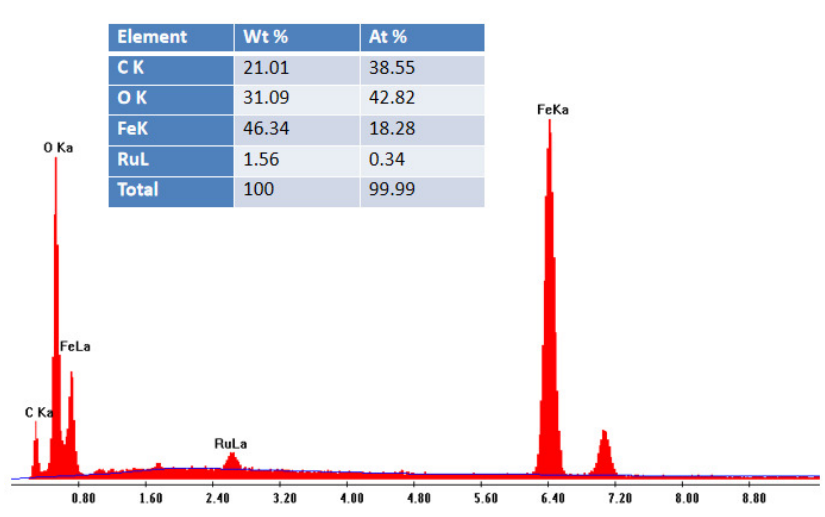

Fig. 4 The EDX spectra of $\mathrm{Fe}_{3} \mathrm{O}_{4} @ \mathrm{Ru}(\mathbf{2 a})$.

by the fading of the yellow color of the $\mathrm{d}_{8}$-toluene and the disappearance of the resonances of $\mathbf{1}$ in the ${ }^{1} \mathrm{H}-\mathrm{NMR}$ after 48 hours (Scheme 4).

The TEM image of the $\mathrm{Fe}_{3} \mathrm{O}_{4} @ \mathrm{Ru}(\mathbf{2 a})$ nanoparticles at high magnification revealed spherical structures, similar to the $\mathrm{Fe}_{3} \mathrm{O}_{4}$ used for its preparation (Fig. 2).

The EDX spectrum of $\mathbf{2 a}$ confirmed the presence of $1.56 \mathrm{w} \%$ ruthenium, as expected (Fig. 4).

In order to protect the magnetic core and retain the magnetic properties, the magnetite can be coated with a non-magnetic and relatively inert layer. Several groups have studied the synthesis of iron oxides $\left(\mathrm{Fe}_{2} \mathrm{O}_{3}\right.$ or $\left.\mathrm{Fe}_{3} \mathrm{O}_{4}\right)$ core-shell nanoparticles by using the Stöber synthesis method from iron salt precursors $[25,26]$ and from preformed iron oxide $[22,27]$. First, we coated the $\mathrm{Fe}_{3} \mathrm{O}_{4}$ nanoparticles with one silica layer by the co-condensation of tetraethyl orthosilicate (TEOS) with the $\mathrm{Fe}-\mathrm{OH}$ groups on the surface resulting in the formation of nonporous $\mathrm{Fe}_{3} \mathrm{O}_{4} @ \mathrm{SiO}_{2}$ particles (Scheme 3). In the same manner, $\mathrm{Fe}_{3} \mathrm{O}_{4} @ \mathrm{SiO}_{2}$ nanoparticles were coated with a second silica layer to give $\mathrm{Fe}_{3} \mathrm{O}_{4} @ \mathrm{SiO}_{2} @ \mathrm{SiO}_{2}$. A third silica layer was added to obtain $\mathrm{Fe}_{3} \mathrm{O}_{4} @ \mathrm{SiO}_{2} @ \mathrm{SiO}_{2} @ \mathrm{SiO}_{2}$ particles.

The TEM images of these silica coated magnetic particles are show on Fig. 5. Both the dark core of $\mathrm{Fe}_{3} \mathrm{O}_{4}$ and the gray layer of silica can be observed. Their average diameters were approximately $100 \mathrm{~nm}$ and the aggregation of individual particles was observed (Fig 5 (a)-(c)).

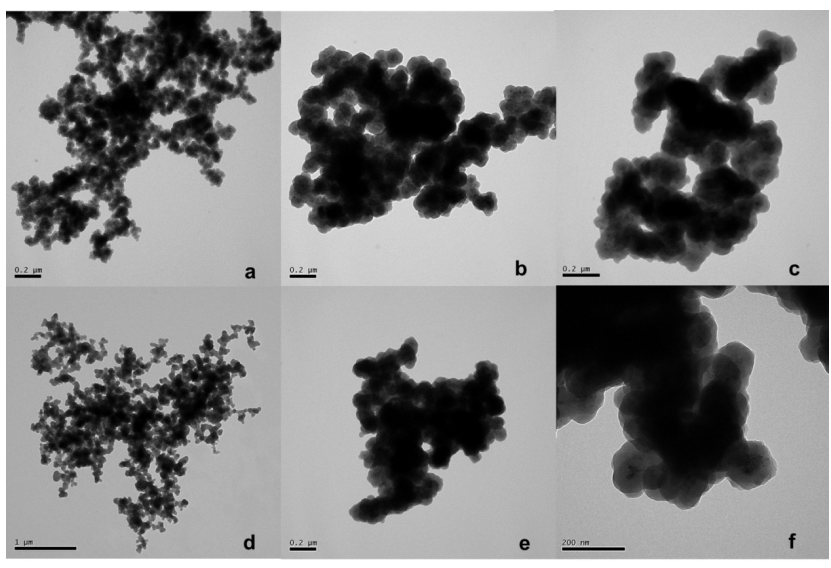

Fig. 5 TEM images of $\mathrm{Fe}_{3} \mathrm{O}_{4} @ \mathrm{SiO}_{2}(\mathrm{a}), \mathrm{Fe}_{3} \mathrm{O}_{4} @ \mathrm{SiO}_{2} @ \mathrm{SiO}_{2}(\mathrm{~b})$, $\mathrm{Fe}_{3} \mathrm{O}_{4} @ \mathrm{SiO}_{2} @ \mathrm{SiO}_{2} @ \mathrm{SiO}_{2}(\mathrm{c}),(\mathbf{2 b})(\mathrm{d}),(\mathbf{2 c})(\mathrm{e})$, and (2d) (f).

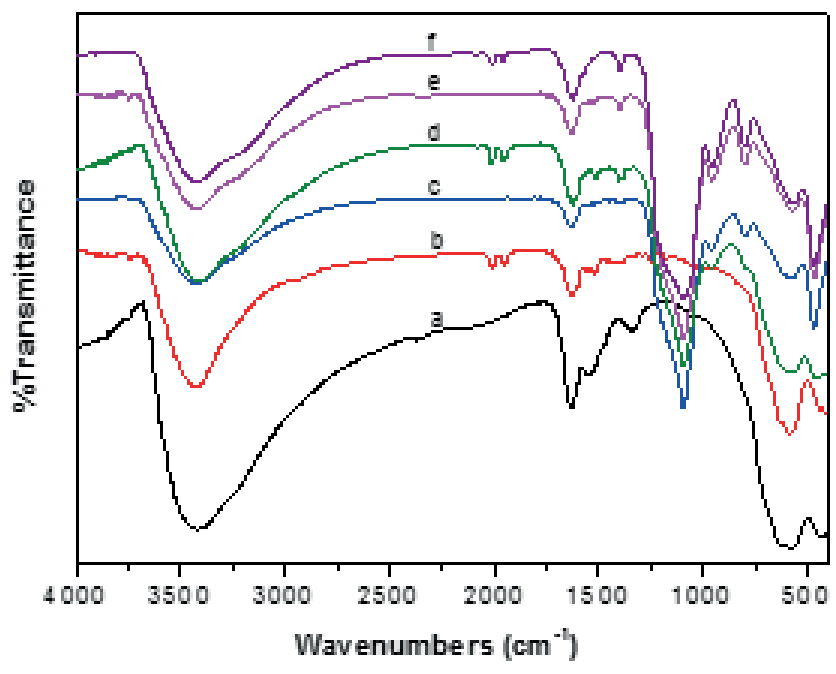

Fig. 6 FT-IR spectra of $\mathrm{Fe}_{3} \mathrm{O}_{4}$ (a), (2a) (b), $\mathrm{Fe}_{3} \mathrm{O}_{4} @ \mathrm{SiO}_{2}$ (c), (2b) (d), $\mathrm{Fe}_{3} \mathrm{O}_{4} @ \mathrm{SiO}_{2} @ \mathrm{SiO}_{2}(\mathrm{e})$, and (2c) (f).

As the number of silica layers increased, the aggregation of particles became denser resulting in bigger particles with non-spherical morphology.

FT-IR of $\mathrm{Fe}_{3} \mathrm{O}_{4}, \mathrm{Fe}_{3} \mathrm{O}_{4} @ \mathrm{SiO}_{2}$ and $\mathrm{Fe}_{3} \mathrm{O}_{4} @ \mathrm{SiO}_{2} @ \mathrm{SiO}_{2}$ (Fig. 6) has confirmed the presence of the silica layers in $\mathrm{Fe}_{3} \mathrm{O}_{4} @ \mathrm{SiO}_{2}$ and $\mathrm{Fe}_{3} \mathrm{O}_{4} @ \mathrm{SiO}_{2} @ \mathrm{SiO}_{2}$, as expected.

The FT-IR of $\mathrm{Fe}_{3} \mathrm{O}_{4}$ (Fig. 6 spectrum a) has showed the characteristic absorption at $591 \mathrm{~cm}^{-1}$ for the Fe-O bond. The broad band at approximately $3431 \mathrm{~cm}^{-1}$ is due to the 
$\mathrm{O}-\mathrm{H}$ stretching vibrations of the surface $\mathrm{Fe}-\mathrm{OH}$ groups. The absorption bands at 1095 and $805 \mathrm{~cm}^{-1}$ (Fig. 6 spectra (c) and (e)) can be assigned to the antisymmetric and symmetric stretching vibrations of the Si-O-Si bonds. In addition, the bands appearing at $953 \mathrm{~cm}^{-1}$ are attributed to the silicon-oxygen symmetrical stretching vibrations of Si-OH groups on the surface. A broad bands at approximately $3424 \mathrm{~cm}^{-1}$ are due to the $\mathrm{O}-\mathrm{H}$ stretching vibrations of surface silanol groups.

The same immobilization procedure was used to attach the functionalized Shvo's ruthenium catalyst precursor 1 to the surface of $\mathrm{Fe}_{3} \mathrm{O}_{4} @ \mathrm{SiO}_{2}, \mathrm{Fe}_{3} \mathrm{O}_{4} @ \mathrm{SiO}_{2} @ \mathrm{SiO}_{2}$ and $\mathrm{Fe}_{3} \mathrm{O}_{4} @ \mathrm{SiO}_{2} @ \mathrm{SiO}_{2} @ \mathrm{SiO}_{2}$ resulting in catalysts 2b, 2c, and $\mathbf{2 d}$, respectively (Fig. 7).

The TEM images of $\mathbf{2} \mathbf{b}-\mathbf{2} \mathbf{d}$ particles indicated that the morphologies of the heterogenized catalysts and the corresponding solid supports were similar (Fig. 5 (d)-(f)).

FT-IR spectroscopy was carried out to observe the successful attachment of Shvo's ruthenium catalyst precursor 1 to the surfaces of the silica-coated MNPs (Fig. 6 spectra (b), (d), and (f)). The characteristic bands of the terminal carbonyl groups attached to the Ru centers in $\mathbf{1}$ were observed at 2014 and $1956 \mathrm{~cm}^{-1}$, as expected.

The powder XRD of $\mathrm{Fe}_{3} \mathrm{O}_{4} @ \mathrm{SiO}_{2} @ \mathrm{SiO}_{2}$ and 2c nanoparticles shows six main diffraction peaks at $2 \theta$ values of $30.22^{\circ}, 36.18^{\circ}, 43.73^{\circ}, 54.09^{\circ}, 57.82^{\circ}$, and $63.42^{\circ}$ (Fig. 8), which can be assigned to the reflection plane indices of inverse cubic spinel structured $\mathrm{Fe}_{3} \mathrm{O}_{4}$. All of the diffraction peaks in the diffraction pattern along with their reflection plane indices are consistent with the reference values [28, 29].
The surface area and porous nature of $\mathbf{2 a - 2 d}$ were studied by $\mathrm{N}_{2}$ adsorption-desorption experiment (Fig. 9). All the four catalysts showed a type IV isotherm according to the IUPAC classification, which indicated that all the tested materials were mesoporous with a hysteresis loop. By increasing the silica-coated layers, the hysteresis loop became shorter and shorter; this corresponded to the decrease in pore volume

Table 1 shows the values of the Brunauer-EmmettTeller (BET) surface area, the pore volume, and the Barrett-Joyner-Halenda (BJH) pore diameter.

Catalyst 2a have the highest surface area and pore volume among the four catalysts. When the number of silica layers coated on the $\mathrm{Fe}_{3} \mathrm{O}_{4}$ surface increased, less surface area and pore volume was obtained. It seems that the silica layer coating reduced the pore volume and surface area.

The catalytic performances of the magnetic catalysts $\mathbf{2 a}-\mathbf{2 d}$ were tested in the transfer hydrogenation reaction of LA with FA to produce 4-HVA, which was in situ dehydrated to form GVL (Scheme 1). In order to compare the catalytic activities of homogeneous and heterogenized catalysts, the catalytic performance of monoruthenium complexes 1 and $\left\{3,4-[p-\mathrm{MeOPh}]_{2}-2,5-\mathrm{Ph}_{2}\left(\eta^{4}-\mathrm{C}_{4} \mathrm{CO}\right)\right\} \mathrm{Ru}(\mathrm{CO})_{3}$ (3) was also investigated (Table 2).

After 24 hours under the same conditions in 1,4-dioxane at $90{ }^{\circ} \mathrm{C}$, the homogeneous catalyst 3 displayed the highest TON, TOF, and GVL yield compared to others; this was in accordance with the general conclusion that the catalytic performances of heterogenized catalysts were often lower than those of their homogeneous analogues. In particular, the homogeneous catalyst $\mathbf{1}$ showed

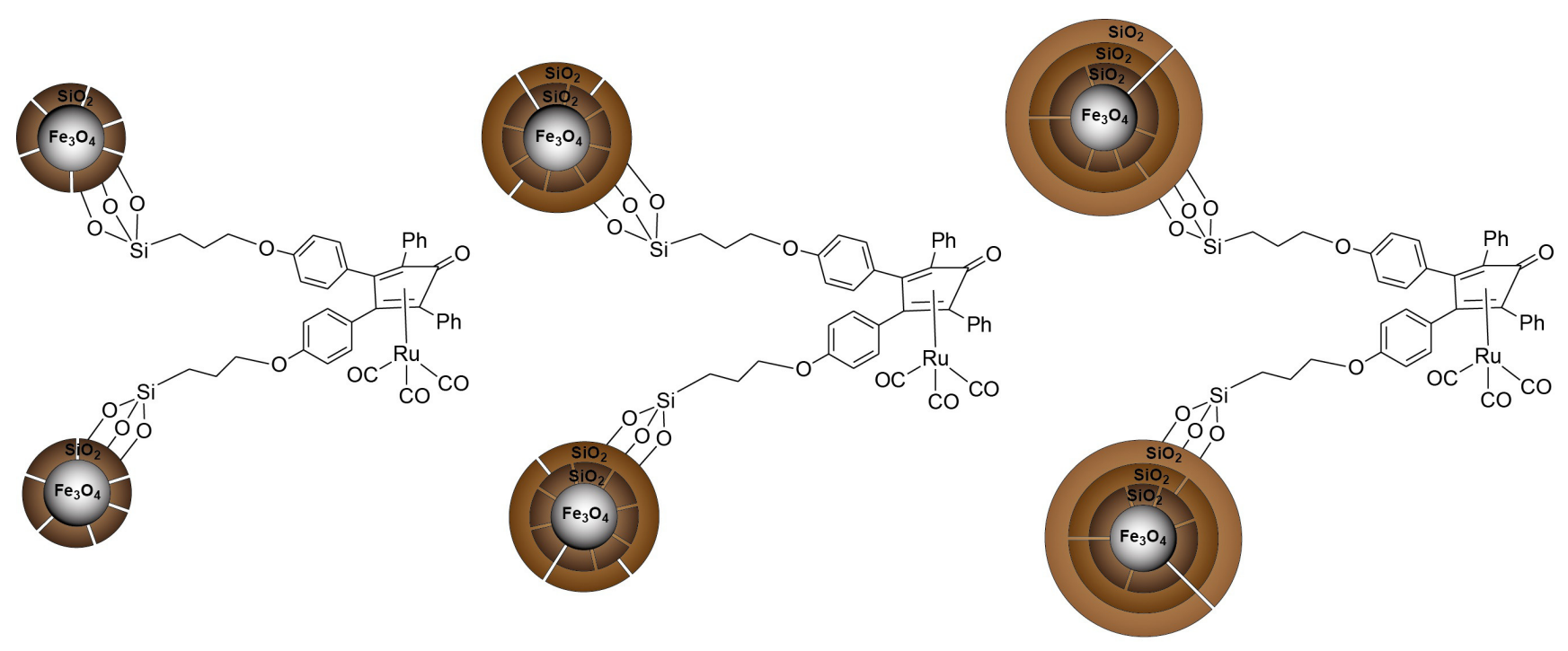

Fig. 7 Magnetic catalyst (2b)-(2d). 


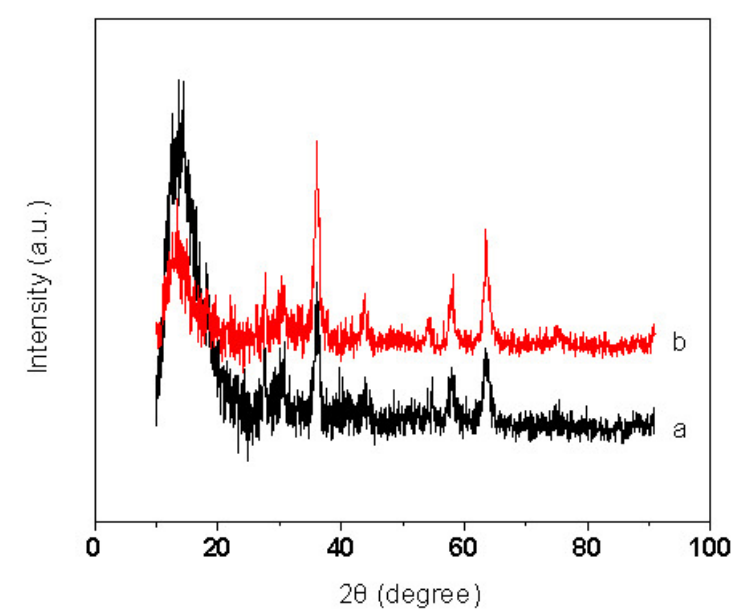

Fig. 8 Powder XRD patterns of $\mathrm{Fe}_{3} \mathrm{O}_{4} @ \mathrm{SiO}_{2} @ \mathrm{SiO}_{2}$ (a) and (2c) (b).

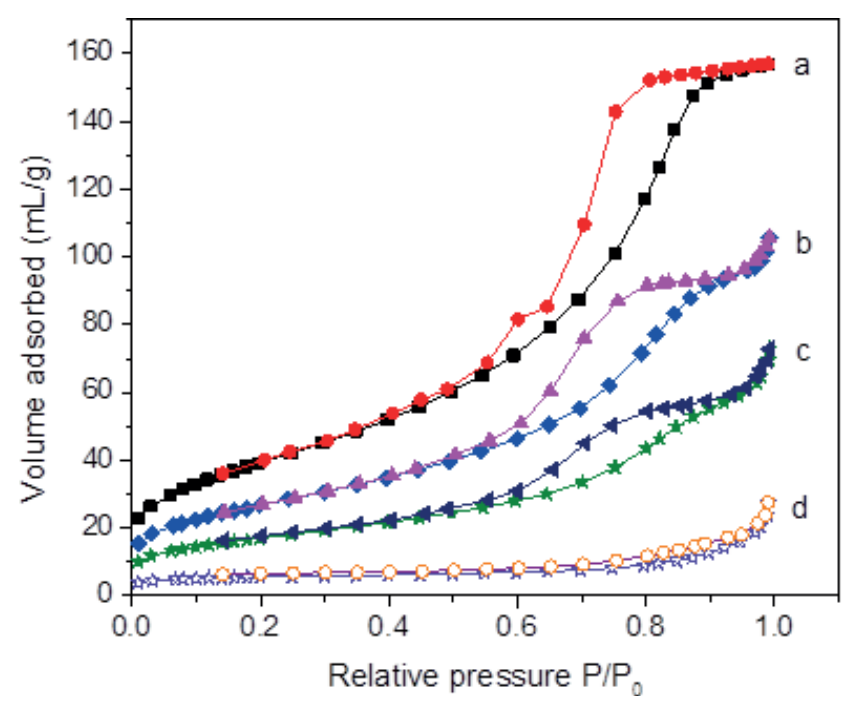

Fig. 9 The $\mathrm{N}_{2}$ adsorption-desorption isotherms of $\mathbf{2 a}(\mathrm{a}), \mathbf{2 b}(\mathrm{b}), \mathbf{2 c}$ (c), and $2 \mathbf{d}(\mathrm{d})$.

Table 1 Textural properties and loading of $\mathbf{2 a - 2 d}$.

\begin{tabular}{lcccc}
\hline Cat. & $\begin{array}{c}\mathrm{S}_{\mathrm{BET}} \\
{\left[\mathrm{m}^{2} / \mathrm{g}\right]}\end{array}$ & $\begin{array}{c}\text { Pore volume } \\
{\left[\mathrm{cm}^{2} / \mathrm{g}\right]}\end{array}$ & $\begin{array}{c}\mathrm{D}_{\mathrm{BJH}} \\
{[\mathrm{nm}]}\end{array}$ & $\begin{array}{c}\text { Cat. loading } \\
{[\mathrm{mmol} / \mathrm{g}]}\end{array}$ \\
\hline $\mathbf{2 a}$ & 141.98 & 0.25 & 5.49 & 0.11 \\
$\mathbf{2 b}$ & 95.94 & 0.17 & 6.81 & 0.13 \\
$\mathbf{2 c}$ & 60.03 & 0.12 & 7.51 & 0.08 \\
2d & 17.88 & 0.04 & 9.56 & 0.09 \\
\hline
\end{tabular}

the lowest activity, which could be explained by the presence of the triethoxysilyl-propyl functional group, which could reacted with water in the system to form the trihydroxysilylpropyl functional group and ethanol, which may have inhibited the activity of the catalyst.

In order to develop a greener system, we have tested the use of a solvent free reaction environment (Table 3). In order to minimize the possible negative effect of the known slow decomposition of FA during a much longer reaction time (120 hours), the ratio of FA:LA was increased to 2.5.
Table 2 Transfer hydrogenation of $1.28 \mathrm{~g}$ of LA (11.02 mmol) with $1.14 \mathrm{~g}$ of FA ( $24.77 \mathrm{mmol})$ in $4 \mathrm{~mL}$ of 1,4-dioxane in the presence of homogeneous or heterogenized Shvo's catalysts at $90{ }^{\circ} \mathrm{C}$ after 24 hours.

\begin{tabular}{lccc}
\hline Catalyst & TON & TOF $\left[h^{-1}\right]$ & GVL [\%] \\
\hline $\mathbf{1}$ & 41 & 2 & 11 \\
$\mathbf{2 a}$ & 122 & 5 & 33 \\
$\mathbf{2 b}$ & 186 & 8 & 50 \\
$\mathbf{2 c}$ & 208 & 9 & 56 \\
$\mathbf{2 d}$ & 197 & 8 & 53 \\
$\mathbf{3}$ & 326 & 14 & 88 \\
\hline
\end{tabular}

Table 3 Transfer hydrogenation of $2 \mathrm{~g}$ of LA $(17.2 \mathrm{mmol})$ and $2 \mathrm{~g}$ of FA (43.4 mmol) without solvent in the presence of heterogenized Shvo's catalysts at $90^{\circ} \mathrm{C}$ after 120 hours.

\begin{tabular}{lccc}
\hline Catalyst & TON & TOF $\left[h^{-1}\right]$ & GVL [\%] \\
\hline 2a & 666 & 6 & 89 \\
2b & 711 & 6 & 95 \\
2c & 726 & 6 & 97 \\
2d & 711 & 6 & 95 \\
\hline
\end{tabular}

Generally, catalysts supported on the silica-coated magnetic nanoparticles showed higher activity than that supported on $\mathrm{Fe}_{3} \mathrm{O}_{4}$. This was probably caused by the different average pore diameters of the support. Larger pores allow fast access of substrates to the catalytic sites in the pores. According to the average pore size, which was calculated by BJH method in Table 1, 2a has a smaller pore size than $\mathbf{2 b}, \mathbf{2 c}$, and $\mathbf{2 d}$. By increasing the reaction time from 24 to 120 hours, most of the levulinic acid will be converted into GVL in the absence of 1,4-dioxane, and the yield of GVL could reach as high as $97 \%$. There were no obvious differences in TONs and TOFs, and the GVL yield of $\mathbf{2 b}, \mathbf{2 c}$, and $\mathbf{2 d}$ indicating that the number of silica layers on the magnetite have little influence.

In a solid-liquid catalysis system, leaching of a catalyst from a solid support is often one of the greatest challenges that could prohibit the industrial application of a heterogenized catalyst. The leaching of Ru and Fe after each transfer hydrogenation reaction of LA with FA in the presence of heterogenized Shvo's catalysts $2 \mathbf{a}-\mathbf{2 d}$ at $90{ }^{\circ} \mathrm{C}$ for 24 hours or 120 hours was analyzed by ICP-MS. The results are summarized in Table 4.

Catalyst 2a had the most serious Fe leaching of the four catalysts, and $\mathrm{Fe}$ leaching was more serious than Ru leaching. After 120 hours the Fe leaching reached as high as $41 \%$. The high leaching is most likely caused by FA because it is more acidic than LA. It probably reacted with $\mathrm{Fe}_{3} \mathrm{O}_{4}$ to release $\mathrm{Fe}^{3+}$, which is why the color of the 
Table $4 \mathrm{Ru}$ and Fe leaching after each transfer hydrogenation of $2 \mathrm{~g}$ of LA (17.2 mmol) with $2 \mathrm{~g}$ of FA (43.4 $\mathrm{mmol})$ in the presence of $\mathbf{2 a}-\mathbf{2 d}$ without any solvent at $90{ }^{\circ} \mathrm{C}$ for specified times.

\begin{tabular}{cccccc}
\hline \multirow{2}{*}{ Cat. } & n (FA) & \multicolumn{2}{c}{ Ru-leaching [\%] } & \multicolumn{2}{c}{ Fe-leaching [\%] } \\
& $\mathrm{n}(\mathrm{Cat})$ & $24 \mathrm{~h}$ & $120 \mathrm{~h}$ & $24 \mathrm{~h}$ & $120 \mathrm{~h}$ \\
\hline 2a & 816 & 6.9 & 28.0 & 8.4 & 41.0 \\
2b & 1870 & 1.7 & 4.5 & 1.5 & 9.5 \\
2c & 1870 & 0.5 & 2.6 & 0.1 & 1.6 \\
2d & 1870 & 0.4 & 1.8 & 0.1 & 1.3 \\
\hline
\end{tabular}

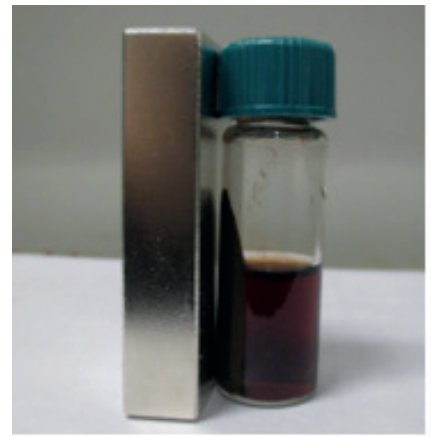

(a)

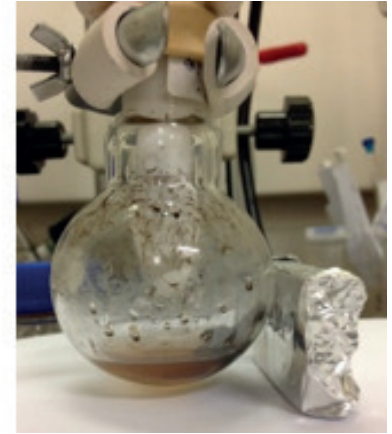

(b)
Fig. 10 Recovery of catalysts $\mathbf{2 a}$ (a) and $\mathbf{2 b}$ (b) by magnetic decantation after conversion of LA and FA to GVL.

solution in the presence of $\mathbf{2} \mathbf{a}$ and $\mathbf{2} \mathbf{b}$ was red and light brown, respectively (Fig. 10).

For silica-coated magnetite supports, less Fe leaching was detected when the number of silica layers coated was high. It seems that the coating of silica layers prevented the leaching of Fe from the magnetite core. However, even with three layers of silica, Fe leaching still occurred. This was probably due to the irregular coreshell structure of the supports. In other words, the $\mathrm{Fe}_{3} \mathrm{O}_{4}$ core was not completely wrapped by silica layers; some cracks in each layer allowed formic acid to access the $\mathrm{Fe}_{3} \mathrm{O}_{4}$ core. Such cracks may capture the free complex 1 during the immobilization procedure, and the immobilized $\mathbf{2 a}$ is not easily washed off by solvents from the cracks. However, when the immobilized catalyst was used for the transfer hydrogenation reaction of LA with FA under heating and mechanical stirring conditions, the immobilized 1 was removed from the cracks. Moreover, when a greater number of silica layers coated the surface of $\mathrm{Fe}_{3} \mathrm{O}_{4}$, fewer cracks were distributed. That's why the Ru leaching decreased with an increasing number of silica layers on the solid support (Table 4).

In addition to the ICP-MS analysis, hot filtration test is another technique can be used to test catalyst leaching from the solid support in the solid-liquid catalytic system [30].
Table 5 Hot filtration test of heterogenized catalysts $\mathbf{2 c}$ and $\mathbf{2 d}$ $1.28 \mathrm{~g}$ of LA (11.02 mmol) and $1.14 \mathrm{~g}$ of FA $(24.77 \mathrm{mmol})$ in $2 \mathrm{~mL}$ of $\mathrm{d}_{6}$-DMSO at Cat./LA $=1: 371$.

\begin{tabular}{lcccc}
\hline Cat. & $\begin{array}{c}\text { Cat. } \\
{[\mathrm{mmol} / \mathrm{g}]}\end{array}$ & $\begin{array}{c}\text { GVL at hot } \\
\text { filtration }[\%]\end{array}$ & GVL at the end point [\%] \\
\hline \multirow{2}{*}{ 2c } & 0.08 & 51 & Remaining & 76 \\
& & & Filtered & 51 \\
2d & 0.09 & 48 & Remaining & 77 \\
& & & Filtered & 48 \\
\hline
\end{tabular}

To ensure that the catalytic activity comes from the immobilized catalyst and not from some active species leached from the solid support to the solution, we examined the transfer hydrogenation of LA with FA at $90{ }^{\circ} \mathrm{C}$ in the presence of the most robust catalysts $\mathbf{2 c}$ and $\mathbf{2 d}$. After 24 hours, half of each reaction mixture was filtered at the reaction temperature, and the conversion of GVL was measured by quantitative ${ }^{1} \mathrm{H}-\mathrm{NMR}$ (Table 5). Both half portions were heated at $90{ }^{\circ} \mathrm{C}$ for another 24 hours. The portion remaining with the catalyst showed an increased yield of GVL, while the filtered portion without the catalyst showed no change of the GVL yield. Therefore, the catalytic activity came from the supported catalyst and not from some species in the solution.

The recyclability of the Shvo's catalyst 2c was investigated because it showed the highest efficiency for the conversion of LA to GVL. Before reusing the catalyst 2a, the flask was placed in proximity to an external magnet, and the reaction mixture was separated from the catalyst with a Pasteur pipette. LA (11.02 mmol), FA (24.77 mmol), and $4 \mathrm{~mL}$ of 1,4-dioxane were added, and the external magnet was removed from the proximity of the flask to start a new experiment. After following a procedure similar to the first cycle with the GVL yield $53 \%$, the yields of the second and third cycles were $52 \%$ and $47 \%$, respectively.

\section{Conclusions}

We prepared four magnetic catalysts $\mathbf{2 a}-\mathbf{2 d}$ by the covalent attachment of Shvo's ruthenium catalyst precursor $\left\{3,4-\left[p-(\mathrm{EtO})_{3} \mathrm{Si}\left(\mathrm{CH}_{2}\right)_{3} \mathrm{OPh}\right]_{2}-2,5-\mathrm{Ph}_{2}\left(\eta^{4}-\mathrm{C}_{4} \mathrm{CO}\right)\right\} \mathrm{Ru}(\mathrm{CO})_{3}(\mathbf{1})$ to the surfaces of $\mathrm{Fe}_{3} \mathrm{O}_{4}, \mathrm{Fe}_{3} \mathrm{O}_{4} @ \mathrm{SiO}_{2}, \mathrm{Fe}_{3} \mathrm{O}_{4} @ \mathrm{SiO}_{2} @ \mathrm{SiO}_{2}$, and $\mathrm{Fe}_{3} \mathrm{O}_{4} @ \mathrm{SiO}_{2} @ \mathrm{SiO}_{2} @ \mathrm{SiO}_{2}$. These catalysts were characterized by TEM, FT-IR, EDX spectroscopy, powder XRD, BET surface area analysis, and BJH pore size and volume analysis. Their catalytic performances were tested in the conversion of LA to GVL with FA as the hydrogen source. Catalysts can be easily isolated from the reaction mixture by using an external magnet that allows fast and efficient separation of the product and the catalyst compared to traditional 
separation protocols. Catalysts immobilized to silica-coated magnetic nanoparticles showed higher activity than that of on $\mathrm{Fe}_{3} \mathrm{O}_{4}$. There were no significant differences in TONs, TOFs, and GVL yield among $\mathbf{2} \mathbf{b}-\mathbf{2 d}$. The leaching test for the four catalysts showed that the silica layer coating on the magnetite prevented the $\mathrm{Fe}$ leaching from the $\mathrm{Fe}_{3} \mathrm{O}_{4}$ core to some extent. When the number of silica layers coating the surface was high, there was less leaching of Fe. The hot filtration test established that the catalytic activity came from the supported catalyst and not from some active species leached from the solid support to the solution. The recyclability of $\mathbf{2 c}$ showed that it could be reused several times without any significant loss of catalytic activity.

\section{References}

[1] Horváth, I. T. "Sustainable Chemistry", Chemical Reviews, 118(2), pp. 369-371, 2018. https://doi.org/10.1021/acs.chemrev.7b00721

[2] Tuck, C. O., Perez, E., Horváth, I. T., Sheldon, R. A., Poliakoff, M. "Valorization of Biomass: Deriving More Value from Waste", Science, 337(6095), pp. 695-699, 2012. https://doi.org/10.1126/science.1218930

[3] Werpy, T., Petersen, G., Aden, A., Bozell, J., Holladay, J., White, J., Manheim, A. "Top Value Added Chemicals from Biomass: Volume 1: Results of Screening for Potential Candidates from Sugars and Synthesis Gas", National Renewable Energy Laboratory, Golden, CO, USA, Rep. NREL/TP-510-35523, 2004. [online] Available at: https://www.nrel.gov/docs/fy04osti/35523.pdf [Accessed: 29 March 2020]

[4] Lui, M. Y., Wong, C. Y. Y., Choi, A. W. T., Mui, Y. F., Qi, L., Horváth, I. T. "Valorization of Carbohydrates of Agricultural Residues and Food Wastes: A Key Strategy for Carbon Conservation", ACS Sustainable Chemistry \& Engineering, 7(21), pp. 17799-17807, 2019.

https://doi.org/10.1021/acssuschemeng.9b04242

[5] Wang, Y., Pedersen, C. M., Deng, T., Qiao, Y., Hou, X. "Direct conversion of chitin biomass to 5-hydroxymethylfurfural in concentrated $\mathrm{ZnCl}_{2}$ aqueous solution", Bioresource Technology, 143, pp. $384-390,2013$.

https://doi.org/10.1016/j.biortech.2013.06.024

[6] Horvat, J., Klaić, B., Metelko, B., Šunjić, V. "Mechanism of levulinic acid formation", Tetrahedron Letters, 26(17), pp. 2111-2114, 1985. https://doi.org/10.1016/S0040-4039(00)94793-2

[7] Srivastava, S., Solanki, N., Mohanty, P., Shah, K. A., Parikh, J. K., Dalai, A. K. "Optimization and Kinetic Studies on Hydrogenation of Furfural to Furfuryl Alcohol over SBA-15 Supported Bimetallic Copper-Cobalt Catalyst", Catalysis Letters, 145(3), pp. 816-823, 2015.

https://doi.org/10.1007/s10562-015-1488-5

[8] González Maldonado, G. M., Assary, R. S., Dumesic, J. A., Curtiss, L. A. "Experimental and theoretical studies of the acid-catalyzed conversion of furfuryl alcohol to levulinic acid in aqueous solution", Energy \& Environmental Science, 5(5), pp. 6981-6989, 2012. https://doi.org/10.1039/C2EE03465D

\section{Acknowledgement}

This work was funded by the Technology Support Programme of the Innovation and Technology Fund of the Government of the Hong Kong SAR (ITS/079/13). Any opinions, findings, conclusions or recommendations expressed in this material/event (or by members of the project team) do not reflect the views of the Government of the Hong Kong Special Administrative Region, the Innovation and Technology Commission or the Panel of Assessors for the Innovation and Technology Support Programme of the Innovation and Technology Fund. We also thank the Environment and Conservation Fund $(\mathrm{ECF} / 31 / 2014)$ for partial financial support.

[9] Fábos, V., Mika, L. T., Horváth, I. T. "Selective Conversion of Levulinic and Formic Acids to $\gamma$-Valerolactone with the Shvo Catalyst", Organometallics, 33(1), pp. 181-187, 2014. https://doi.org/10.1021/om400938h

[10] Horváth, I. T., Mehdi, H., Fábos, V., Boda, L., Mika, L. T. " $\gamma$-Valerolactone-a sustainable liquid for energy and carbon-based chemicals", Green Chemistry, 10(2), pp. 238-242, 2008. https://doi.org/10.1039/B712863K

[11] Collis, A. E. C., Horváth, I. T. "Heterogenization of Homogeneous Catalytic Systems", Catalysis Science \& Technology, 1(6), pp. 912-919, 2011. https://doi.org/10.1039/c1cy00174d

[12] Wang, D., Astruc, D. "Fast-Growing Field of Magnetically Recyclable Nanocatalysts", Chemical Reviews, 114(14), pp. 6949-6985, 2014. https://doi.org/10.1021/cr500134h

[13] Öztürk, B. Ö. "Ammonium tagged Hoveyda-Grubbs catalysts immobilized on magnetically separable core-shell silica supports for ring-closing metathesis reaction", Microporous and Mesoporous Materials, 267, pp. 249-256, 2018. https://doi.org/10.1016/j.micromeso.2018.04.002

[14] Öztürk, B. Ö., Gürcü, D., Şehitoğlu, S. K. "Carboxylic acid addition to terminal alkynes utilizing ammonium tagged HoveydaGrubbs catalyst supported on magnetically separable core/shell silica: A highly reusable and air compatible catalytic system", Journal of Organometallic Chemistry, 883, pp. 11-16, 2019. https://doi.org/10.1016/j.jorganchem.2019.01.005

[15] Shvo, Y., Czarkie, D., Rahamim, Y., Chodosh, D. F. "A new group of ruthenium complexes: structure and catalysis", Journal of the American Chemical Society, 108(23), pp. 7400-7402, 1986. https://doi.org/10.1021/ja00283a041

[16] Choi, J. H., Kim, N., Shin, Y. J., Park, J. H., Park, J. "Heterogeneous Shvo-type ruthenium catalyst: dehydrogenation of alcohols without hydrogen acceptors", Tetrahedron Letters, 45(24), pp. 4607-4610, 2004 https://doi.org/10.1016/j.tetlet.2004.04.113 
[17] Hanna, D. G., Shylesh, S., Parada, P. A., Bell, A. T. "Hydrogenation of butanal over silica-supported Shvo's catalyst and its use for the gas-phase conversion of propene to butanol via tandem hydroformylation and hydrogenation", Journal of Catalysis, 311, pp. 52-58, 2014. https://doi.org/10.1016/j.jcat.2013.11.012

[18] He, D., Horváth, I. T. "Application of silica-supported Shvo's catalysts for transfer hydrogenation of levulinic acid with formic acid", Journal of Organometallic Chemistry, 847, pp. 263-269, 2017. https://doi.org/10.1016/j.jorganchem.2017.05.039

[19] Mantovani, A., Cenini, S., James, B. R., Plackett, D. V. "Dodecacarbonyltriruthenium", Inorganic Syntheses, 16, pp. 47-48, 1976. https://doi.org/10.1002/9780470132470.ch14

[20] Booth, B. L., Ofunne, G. C., Stacey, C., Tait, P. J. T. "Silicasupported cyclopentadienyl-rhodium(I), -cobalt(I), and -titanium(IV) complexes", Journal of Organometallic Chemistry, 315(2), pp. 143-156, 1986.

https://doi.org/10.1016/0022-328X(86)80433-8

[21] Gleeson, O., Davies, G. L., Peschiulli, A., Tekoriute, R., Gun'ko, Y. K., Connon, S. J. "The immobilisation of chiral organocatalysts on magnetic nanoparticles: the support particle cannot always be considered inert", Organic \& Biomolecular Chemistry, 9(22), pp. 7929-7940, 2011. https://doi.org/10.1039/C1OB06110K

[22] Hui, C., Shen, C., Tian, J., Bao, L., Ding, H., Li, C., Tian, Y., Shi, X., Gao, H. J. "Core-shell $\mathrm{Fe}_{3} \mathrm{O}_{4} @ \mathrm{SiO}_{2}$ nanoparticles synthesized with well-dispersed hydrophilic $\mathrm{Fe}_{3} \mathrm{O}_{4}$ seeds", Nanoscale, 3(2), pp. 701-705, 2011. https://doi.org/10.1039/C0NR00497A

[23] Shylesh, S., Schünemann, V., Thiel, W. R. "Magnetically Separable Nanocatalysts: Bridges between Homogeneous and Heterogeneous Catalysis", Angewandte Chemie: International Edition, 49(20), pp. 3428-3459, 2010.

https://doi.org/10.1002/anie.200905684

[24] Mrówczyński, R., Nan, A., Liebscher, J. "Magnetic nanoparticle-supported organocatalysts - an efficient way of recycling and reuse", RSC Advances, 4(12), pp. 5927-5952, 2014.

https://doi.org/10.1039/C3RA46984K
[25] Zhao, W., Gu, J., Zhang, L., Chen, H., Shi, J. "Fabrication of Uniform Magnetic Nanocomposite Spheres with a Magnetic Core/ Mesoporous Silica Shell Structure", Journal of the American Chemical Society, 127(25), pp. 8916-8917, 2005. https://doi.org/10.1021/ja051113r

[26] Hajipour, A., Azizi, G. "Fabrication of covalently functionalized mesoporous silica core-shell magnetite nanoparticles with palladium(II) acetylacetonate: application as a magnetically separable nanocatalyst for Suzuki cross-coupling reaction of acyl halides with boronic acids", Applied Organometallic Chemistry, 29(4), pp. 247-253, 2015. https://doi.org/10.1002/aoc.3280

[27] Movassagh, B., Takallou, A., Mobaraki, A. "Magnetic nanoparticle-supported Pd(II)-cryptand 22 complex: An efficient and reusable heterogeneous precatalyst in the Suzuki-Miyaura coupling and the formation of aryl-sulfur bonds", Journal of Molecular Catalysis A: Chemical, 401, pp. 55-65, 2015. https://doi.org/10.1016/j.molcata.2015.03.002

[28] Sahoo, B., Devi, K. S. P., Sahu, S. K., Nayak, S., Maiti, T. K., Dhara, D., Pramanik, P. "Facile preparation of multifunctional hollow silicananoparticles and their cancer specific targeting effect", Biomaterials Science, 1(6), pp. 647-657, 2013. https://doi.org/10.1039/C3BM00007A

[29] Ray Chowdhuri, A., Bhattacharya, D., Sahu, S. K. "Magnetic nanoscale metal organic frameworks for potential targeted anticancer drug delivery, imaging and as an MRI contrast agent", Dalton Transactions, 45(7), pp. 2963-2973, 2016. https://doi.org/10.1039/C5DT03736K

[30] Lempers, H. E. B., Sheldon, R. A. "The Stability of Chromium in CrAPO-5, CrAPO-11, and CrS-1 during Liquid Phase Oxidations", Journal of Catalysis, 175(1), pp. 62-69, 1998. https://doi.org/10.1006/jcat.1998.1979 